\title{
Epicrania Fugax
}

\author{
Çetin Kürşad AKPINAR', Hakan DOĞRU², Taner ÖZBENLi² \\ 'Clinic of Neurology, Vezirköprü State Hospital, Samsun, Turkey \\ 2Department of Neurology, Ondokuz Mayıs University School of Medicine, Samsun, Turkey
}

Dear Editor,

Epicrania fugax has recently been defined as a paroxysmal headache localized in the posterior cranial area, which starts at a focal area and rapidly radiates ipsilaterally around the eye or the nose $(1,2)$. Autonomic findings can accompany some cases $(2,3)$. In this syndrome, the average onset age of which is 48 years, the pathogenesis has not been fully enlightened. Its treatment is similar to the treatment of neuralgiform pains. In this article, a case who was diagnosed with epicrania fugax, a newly defined primary headache, and who responded to gabapentin ( $800 \mathrm{mg} /$ day) treatment was presented.

A 59-year-old female patient presented to our neurology polyclinic with a complaint of headache that had persisted for 2 years. The headache was moderate or severe, it lasted 5-10 s, it started from the right side of the back of the head and radiated to the eye, it was a stabbing type of pain, it was accompanied with lachrymation, and its attack frequency was 2-3 times a day. Neurological and other system examinations were normal. There was no risk factor other than hypertension. Contrast brain-diffusion magnetic resonance imaging and magnetic resonance angiography examinations were normal. No pathology was found in the laboratory examinations. The patient did not respond to indomethacin ( $150 \mathrm{mg} /$ day) and carbamazepine $(600 \mathrm{mg} /$ day) treatments. The case whose headache was reconsidered was thought to have epicrania fugax. Our patient who began to have less headaches with the treatment of gabapentin $1800 \mathrm{mg} /$ day is still being followed by our polyclinic.

Epicrania fugax was first defined by Pareja et al. ( I) in 2008. Although there were only 20 cases defined until 2009, this number has currently increased to $100(1,2,3)$. Its characteristics that differentiate it from other epicranias and neuralgiform aches are the origin of the headache, its duration, and how it radiates (4). The type of headache that can be confused the most with epicrania fugax is the short-term, one-sided neuralgiform headache accompanied by autonomic findings; however, this type of headache does not radiate (5). Although its pathogenesis is not fully known, peripheral and central mechanisms are thought to play a role $(1,2)$. Case reports show responses to the treatments of occipital nerve block, carbamazepine, lamotrigine, pregabalin, and gabapentin $(1,2,3)$.

In one-sided, short-term headaches that start from a focal region at the back of the head and quickly radiate to the nose and the eye, epicrania fugax, which is a newly defined type of headache, should be considered.

Conflict of Interest: No conflict of interest was declared by the authors.

Financial Disclosure: The authors declared that this study has received no financial support.

\section{REFERENCES}

I. Pareja JA, Cuadrado ML, Fernandez-De-Las Penas C, Caminero AB, Nieto C, Sanchez C, Sols M, Porta-Etessam J. Epicrania fugax: An ultrabrief paroxysmal epicranial pain. Cephalalgia 2008; 28:257-263. [CrossRef]

2. Guerrero AL, Cuadrado ML, Porta-Etessam J, Garcia-Ramos R, Gomez-Vicente L, Herrero S, Pe-as ML, Fernández R. Epicrania fugax: Ten new and therapeutic results. Headache 20 10; 50:45I-458. [CrossRef]

3. Cuadrado ML, Ordás CM, Sánchez-Lizcano M, Casas-Limón J, Matías-Guiu JA, García-García ME, Fernández-Matarrubia M, Barahona-Hernando R, Porta-Etessam J. Epicrania Fugax: 19 Cases of an Emerging Headache. Headache 2013; 53:764-774. [CrossRef]

4. Sjaastad O, Pettersen H, Bakketeig LS. The vaga study of headache epidemiology II. Jabs: Clinical manifestations. Acta Neurol Scand 2002; I05:25-3I. [CrossRef]

5. Cohen AS, Mathura MS, Goadsby P. Short-lasting unilateral neuralgiform headache attacks with conjunctival injection and tearing (SUNCT) or cranial autonomic features (SUNA). A prospective clinical study of SUNCT and SUNA. Brain 2003; 126:180 I-1813. 